\title{
Prosocial consequences of third-party anger
}

\author{
Janne van Doorn ${ }^{1}$ - Marcel Zeelenberg ${ }^{2,3}$. \\ Seger M. Breugelmans ${ }^{2}$. Sebastian Berger ${ }^{4}$. \\ Tyler G. Okimoto 5
}

\begin{abstract}
Anger has traditionally been associated with aggression and antagonistic behavior. A series of studies revealed that experiences of third-party anger (anger experienced when observing that harm is done to someone) can also lead to prosocial behavior. More specifically, three studies, hypothetical scenarios as well as a behavioral study, revealed that third-party anger can promote compensation of the victim. The results also showed a preference for such prosocial behaviors over antagonistic behaviors. We conclude that behaviors stemming from anger, whether antagonistic or prosocial, are reactions to inequity, albeit determined by the constraints of the situation.
\end{abstract}

Keywords Third-party anger · Prosocial · Compensation · Punishment · Inequity

\section{Introduction}

Anger is one of the most frequently experienced emotions (e.g., Schimmack and Diener 1997). It is elicited by events that are unpleasant or undesired, such as situations of goal obstruction, injustice, or unfairness (e.g., Berkowitz and Harmon-Jones 2004; Frijda 1986, 1987; Kuppens et al. 2003; Scherer 1993). Because of its prevalence and because the experience of anger typically involves negative situations and feelings, it

$凶 \quad$ Janne van Doorn

janne.vdoorn@gmail.com

1 Department of Criminology, Leiden University, PO Box 9520, 2300 RA Leiden, The Netherlands

2 Tilburg University, Tilburg, The Netherlands

3 VU Amsterdam, Amsterdam, The Netherlands

4 University of Bern, Bern, Switzerland

5 University of Queensland, Brisbane, Australia 
is not surprising that this emotion has long been seen as one of the most exemplary negative emotions (e.g., Averill 1982; Berkowitz 1990; Izard 1991; Russell 1991).

Interestingly, the behaviors that angry people display appear to be diverse and not so unambiguously negative. Anger is an approach-motivated emotion (Carver and Harmon-Jones 2009) that brings forth an effort to remove the violation of what 'ought' to be (Frijda 1986). Studies have suggested that this approach motivation can take the form of aggressive, punitive, and antagonistic behaviors (e.g., Bougie et al. 2003; Darley and Pittman 2003; Fischer and Roseman 2007; Lemay et al. 2012; Lotz et al. 2011a; Nelissen and Zeelenberg 2009; Pillutla and Murnighan 1996; Rimé 2009; Roseman et al. 1994; Coillie and Mechelen 2006; Wetzer et al. 2007). Although this classical view of anger clearly dominates the literature, there are mixed findings suggesting positive outcomes as well. Specifically, there is some evidence that anger can promote positive behaviors such as social sharing, compensation to a victim, and helping the disadvantaged (e.g., Iyer et al. 2007; Lotz et al. 2011a, b; Wakslak et al. 2007).

Still, research showing a direct relation between anger and prosocial or helping behaviors is lacking (for a review, see Van Doorn et al. 2014). In this paper we examine the effect of anger on subsequent prosocial behavior of third-parties and seek to explain both antagonistic and prosocial consequences of anger in terms of equityrepair concerns. Before we describe the rationale of our studies it is useful to note that in this article we use the term prosocial behavior to refer to behavior aimed at helping a victim in order to restore equity. We do not propose that anger leads to a general tendency to act prosocially to anyone or at any time. In fact, as we explain below, we believe it is crucial to differentiate between first- and third-party anger to understand the various behavioral expressions of anger.

\section{First-party and third-party anger}

We can experience anger both as a result of the harm done to ourselves (first-party anger) and as a result of the harm done to someone else (third-party anger). Although first- and third-party anger might feel similar, there are reasons to believe that the behaviors that follow from these emotional experiences are different. With this we do not suggest that there are necessarily two different forms of anger; instead we argue that different situations offer different behavioral constraints and affordances for the expression of anger's approach-motivation (cf., Frijda and Zeelenberg 2001). For example, being angry after unjustly receiving a disadvantageously low amount of money (first-person victim) could lead to the restoration of equity by punishing the perpetrator who distributed the money. Being angry because someone else unjustly received a disadvantageously low amount of money (third-party observer) could lead to the restoration of equity by punishing the perpetrator, but also by compensating the 'victim'. Thus, observers of inequity ('third parties') have a wider range of restorative behaviors at their disposal than victims of inequity do. After all, victims can rarely compensate themselves (cf., Feldman Hall et al. 2014).

It has already been shown that various prosocial behaviors aimed at restoring equity may occur in third-party situations. For example, Lotz et al. (2011b) found that people 
generally compensated more than they punished in third-party situations. Furthermore, Leliveld et al. (2012) found that people who scored high on dispositional empathy had a preference for compensating victims instead of punishing perpetrators in these situations. Though these studies have shown that people both compensate and punish, the question is what drives people to act prosocially in triadic situations? We have reason to believe that anger, which has hitherto been associated largely with third-party punishment (e.g., Fehr and Gächter 2002; Lotz et al. 2011b), can also motivate third-party prosocial acts. Both punishment of a perpetrator and compensation of a victim can act as a means to the end of restoring unjust or inequitable relations (e.g., Frijda 2004; Van Doorn et al. 2014). We believe that in interpersonal situations the general concern of anger, namely goal blockage (e.g., Berkowitz and Harmon-Jones 2004; Kuppens et al. 2003), translates into a concern for equity (e.g., Stillwell et al. 2008). This would imply that the behaviors following from anger are aimed at restoring equity. In first-party situations this is often done in an antagonistic manner; however, in third-party situations equity can also be restored in a prosocial manner.

Given that there are multiple ways to right certain wrongs in third-party situations, it is surprising that in experimental research punishment has often been the only option given to participants (e.g., Fehr and Fischbacher 2004; Fehr and Gächter 2002; Nelissen and Zeelenberg 2009). In the few examples in which the research included prosocial options, moral outrage (anger provoked by the perception that a moral standard has been violated; see Batson et al. 2007) correlated substantially with both participants' assignment of perpetrator punishment and victim compensation (Darley and Pittman 2003; Lotz et al. 2011a,b). In a similar vein, Vitaglione and Barnett (2003) found that empathic anger was positively related to both helping a victim and punishing a perpetrator; Montada and Schneider (1989) and Wakslak et al. (2007) found that moral outrage correlates with prosocial activities such as donating money, signing petitions, and supporting social projects in favor of the disadvantaged; and Iyer et al. (2007) suggested that anger aimed at the ingroup predicted compensation to an outgroup. Although all these findings are suggestive of a relationship between third-party anger and prosocial behavior, none of these studies included manipulations of anger. It is important to identify causal effects in order to predict (prosocial) behavior stemming from anger. On the basis of the findings by Lotz et al. (2011b), we might even expect angry people to prefer victim compensation over punishment of a perpetrator as a way of restoring equity. In compensation, the victim is helped out of his/her disadvantageous position; punishing the perpetrator may also restore justice, but this does not take away the harm done to the victim. Thus, compensation of a victim seems to be a more positive approach. Moreover, victim compensation is consistent with the do-no-harm principle (Baron 1995).

We further expect compensation to be a direct result of the anger, which is independent from the empathic concerns that may be triggered simultaneously (Leliveld et al. 2012). Some initial support for this expectation can already be found in the experiment by Lotz et al. (2011b), who found that visibility mattered for empathy: the goal of empathy is to comfort someone, but if the victim does not know about the unfair allocation there is no one to comfort. Visibility, however, did not matter 
for anger, which correlated with the restoration of injustice in all cases. According to Blader and Tyler (2002), justice theory suggests that we feel concerned even when a loathsome person for whom we feel little empathy is the victim of injustice. Although anger was not explicitly mentioned or examined in this relationship, the emotion appraisal literature shows that injustice is indeed an important elicitor of anger (Mikula et al. 1998). Montada and Schneider (1989) even showed that moral outrage was a stronger predictor for prosocial behavior than sympathy, a construct very much related to empathy (Eisenberg and Fabes 1990). Thus, the effects of anger and empathy on compensation are expected to be independent of one another.

In the anger literature one finds several terms referring to anger stemming from outcomes that are not for oneself. We use the term third-party anger as an umbrella term for all these forms of anger. For example, Batson et al. (2007) differentiate between moral outrage (anger provoked by the perception that a moral standard has been violated), personal anger (anger one might feel when one's own interests are thwarted), and empathic anger (when interests of the cared-for other have been thwarted). First-party anger is what Batson et al. would call personal anger, and third-party anger is what they would call empathic anger when it concerns cared-for others such as friends, and moral outrage when it concerns strangers. As argued before, we do not believe that the experiences of anger are different between first-party or third-party anger, but rather its behavioral consequences are because the specific situations allow for different solutions. Studies that did concern behavioral consequences of moral outrage (O'Mara et al. 2011; Montada and Schneider 1989; Wakslak et al. 2007) or empathic anger (Vitaglione and Barnett 2003) all involved situations that we would call third-party anger situations.

\section{The current studies}

We report here three studies using different methods to investigate the behavioral consequences of third-party anger. All methods have proven to be useful for studying emotions and their consequences in previous research. Of course, each method on its own has its idiosyncratic strengths and weaknesses. As a set, though, we suggest that these different methodologies inform us about the potential prosocial consequences of anger. Study 1 provided a first experimental test of whether experiences of anger (via an autobiographical recall) spillover to prosocial behavior in a third-party situation. This study shows that activating anger increases willingness to compensate a victim of unfairness, and that angry people are willing to compensate more than to punish. This study also shows that these effects are independent of trait anger and trait empathy. Study 2 extended this finding by illustrating that angry participants preferred compensation to punishment when forced to choose between the two responses. Finally, Study 3 employs an economic game with real payoffs attached to provide a direct measure of behavior. The results suggest that unfairness triggers anger, which causes third-party interventions despite a direct cost to decision makers. 


\section{Study 1}

\subsection{Method}

${ }^{1}$ Dutch University students (27 males, 94 females, one unspecified, $M_{\text {age }}=20.37$, $\mathrm{SD}=2.11$ ) were randomly assigned to the anger or control condition. Participants completed an autobiographical recall task, describing a situation in which they felt angry (anger condition) or describing a normal day of the week (control condition). Recalling a situation in which a certain emotion was experienced reactivates the emotion and thereby also the motivational tendencies associated with that emotion (e.g., Strack et al. 1985). Furthermore, such recall tasks have been effectively used in previous studies on the behavioral consequences of emotions in experimental economic games (e.g., De Hooge et al. 2008; Martinez and Zeelenberg 2015). Participants first indicated how much anger, happiness, shame, regret, sadness, and guilt they felt $(1=$ not at all, 5 = very strongly) in that situation. They next continued with an unrelated task in which they read the following scenario (translated from the original Dutch):

Imagine: You observe a game played by two players, named Mark and Rick. Mark and Rick are playing a game in which $€ 100$ needs to be divided. Mark gets to decide how to divide this money between himself and Rick. Rick has no influence on the division of the money. Mark decides to give Rick $€ 40$ and to keep $€ 60$.

Then, participants read that they themselves own $€ 50$, and that there are three options to use that money: compensate Rick (every euro that they used for compensation would increase Rick's amount with $€ 3$ ), punish Mark (every euro that they used for punishment would decrease Mark's amount with €3) and/or keep the money themselves (cf. Leliveld et al. 2012). Participants filled in the amount of money spent on punishing Rick, compensating Mark, and the amount they kept for themselves (which needed to add up to $€ 50)^{2}{ }^{2}$

Participants then completed the 7-item empathic concern scale ( $\alpha=0.83$; Davis 1983, 1994, as used in Leliveld et al. 2012), and a trait anger scale based on a shortened version of the trait anger subscale of the State-Trait Anger Expression Inventory $(\alpha=$ 0.87; STAXI; Spielberger 1988). ${ }^{3}$ These additional scales were included for control

\footnotetext{
1 We report all data exclusions (if any), all manipulations, and all measures in the studies. The order of measures reported in the method sections is the same as the order of measures in the original questionnaire provided to participants. Studies 1 and 2 were part of a larger testing session. There were no gender effects in any of the studies. When there was an inequality of variances when testing differences between means using $t$ tests, corrected degrees of freedom are reported throughout the article. Throughout the article we use Cohen's $d$ for effect sizes of $t$ tests. In case of a paired samples $t$ test, we used the following formula to calculate Cohen's $d: t \sqrt{1 / n}$.

2 For exploratory reasons, we also asked participants to motivate their reason for choosing punishment and/or compensation and/or keeping the money themselves in Study 1 and Study 2. The most prevalent reason for choosing punishment or compensation was that participants felt that was "the fairest/equitable thing to do", or that they could use the money themselves when choosing neither punishment nor compensation. However, we do not describe these results in detail here.

3 Items included "I am easily frustrated", "I have a fiery temper", "I am quicktempered", "I am a hotheaded person", "I am easily annoyed".
} 
Table 1 Study 1: anger and monetary division means (and standard deviations) as a function of emotion condition

\begin{tabular}{|c|c|c|c|c|}
\hline & \multicolumn{4}{|l|}{ Condition } \\
\hline & \multicolumn{2}{|l|}{ Anger $(n=63)$} & \multicolumn{2}{|c|}{ Control $(n=59)$} \\
\hline & $M(\mathrm{SD})$ & $95 \% \mathrm{CI}$ & $M(\mathrm{SD})$ & $95 \% \mathrm{CI}$ \\
\hline Anger & $3.67(0.92)^{\mathrm{a}}$ & {$[3.44,3.90]$} & $1.29(0.74)^{\mathrm{b}}$ & {$[1.09,1.48]$} \\
\hline Compensation & $4.49(6.12)^{\mathrm{a}}$ & {$[2.95,6.03]$} & $2.51(3.31)^{\mathrm{b}}$ & {$[1.65,3.37]$} \\
\hline Punishment & $2.46(4.18)^{\mathrm{a}}$ & {$[1.41,3.51]$} & $1.80(2.95)^{\mathrm{a}}$ & {$[1.03,2.56]$} \\
\hline Self & $43.05(7.98)^{\mathrm{a}}$ & {$[41.04,45.06]$} & $45.69(5.23)^{\mathrm{b}}$ & {$[44.33,47.06]$} \\
\hline
\end{tabular}

Anger scores could range from 1 (not at all) to 5 (very strongly). Higher scores indicate higher amounts of euros used to punish/compensate. Means with a different superscript are significantly different with $t \mathrm{~s}>2.20, p \mathrm{~s}<0.03$

reasons because these traits might influence the relation between state anger and compensation or punishment (e.g., Deffenbacher et al. 1996; Leliveld et al. 2012; Vitaglione and Barnett 2003). Finally, participants were thanked, debriefed, and received $€ 8$ or course credit for their participation.

\subsection{Results}

The results are displayed in Table 1. The other emotion means are in the Appendix. Participants in the anger condition reported more anger than participants in the control condition. Participants in the anger condition reported more anger than all other emotions.

Monetary division In the anger condition, out of 63 participants 21 did not use any money for compensation or punishment, 1 only punished, 14 only compensated, and 27 punished and compensated. In the control condition, out of 59 participants 23 did not use any money for compensation or punishment, 4 only punished, 17 only compensated, and 15 punished and compensated. Thus, a total of 78 participants (64\%) engaged in at least one justice response. An ANOVA on the amount of euros spent on compensation revealed a significant effect of condition, $F(1,120)=4.86, p=0.029$, $\eta_{p}^{2}=0.04$. Participants in the anger condition gave more money to compensate Rick than participants in the control condition, but they did not punish Mark more than control participants, $F(1,120)=1.02, p=0.316, \eta_{p}^{2}=0.01$. Furthermore, participants induced with anger spent more money on compensation than punishment, $t(62)=$ 2.37, $p=0.021, d=0.30$. This difference was not significant for control participants, $t(58)=1.58, p=0.119, d=0.21^{4}$

\footnotetext{
${ }^{4}$ There were three extreme outliers (data points that are more extreme than $\mathrm{Q} 1-3 * \mathrm{IQR}$ or $\mathrm{Q} 3+3 *$ IQR) on the compensation and punishment measures, which were all in the anger condition. We chose not to delete these outliers, as we judged these responses as likely and valid, especially because these cases appeared in the same condition and might be considered as more intense reactions to the anger manipulation. However, when deleting these three cases we see a slight adjustment in one of the effects: The effect of condition on compensation becomes marginally significant $\left(F(1,117)=3.14, p=0.079, \eta_{p}^{2}=0.04\right)$.
} 
Traits The scores on empathic concern $(M=3.40, \mathrm{SD}=1.84)$ and on trait anger $(M=$ $6.71, \mathrm{SD}=5.44)$ did not differ between conditions, revealing that the manipulation did not influence the trait measures. Regression analyses showed that empathic concern was related only to the amount of money participants used for compensation, $\beta=$ $0.20, t(120)=2.17, p=0.032$, and not for punishment, $\beta=0.15, t(120)=1.63, p=$ 0.106 . Trait anger was related only to the amount of money participants used to punish, $\beta=0.23, t(121)=2.58, p=0.011$, and not to compensation, $\beta=0.05, t(121)=0.57, p=$ 0.572 .

When entering empathic concern as a covariate in the ANCOVA with Condition as an independent variable and compensation as dependent variable, condition remained significant, $F(1,118)=4.56, p=0.035, \eta_{p}^{2}=0.04$. In addition, when entering trait anger as a covariate in an ANCOVA with Condition as an independent variable and punishment as dependent variable, the results for Condition remain non-significant, $F(1,119)=0.64, p=0.427, \eta_{p}^{2}=0.01$. Thus, controlled for the traits empathic concern and anger, state anger still motivated participants to use higher amounts of money to compensate the victim as compared to participants not experiencing state anger.

\subsection{Discussion}

This study found that inducing anger in participants resulted in an increased amount of money they assigned for compensation. Furthermore, within the anger condition, more money was spent on compensation than on punishment. Put differently, participants who have been induced with anger kept less money for themselves than control participants, and spent more on compensating the victim rather than punishing the perpetrator. These effects occurred independently from participants' empathic concern.

Although Study 1 provided support for a causal link from anger to compensation, it has not yet been shown that compensation is actually the preferred response that follows third-party anger. Study 2 therefore tests which response, compensation or punishment, angry people prefer when they are forced to choose. We used a more unfair version of the scenario from Study 1 as an anger manipulation.

\section{Study 2}

\subsection{Method}

Dutch university students (61 males, 130 females, one unspecified; $M_{\text {age }}=21.06$, SD $=2.62$ ) were randomly assigned to the inequity or equity condition. Participants in the inequity condition read the following scenario (translated from the original Dutch):

Imagine: You observe a game played by two players, named Mark and Rick. Mark and Rick are playing a game in which $€ 100$ needs to be divided. Mark gets to decide how to divide this money between himself and Rick. Rick has no influence on the division of the money. Mark decides to give Rick $€ 20$ and to keep $€ 80$. 
Table 2 Study 2: anger means (and standard deviations) and percentages of monetary division chosen as a function of emotion condition

\begin{tabular}{lll}
\hline & Condition & \\
\cline { 2 - 3 } & $\begin{array}{ll}\text { Inequity }(n=95) \\
M(\mathrm{SD})\end{array}$ & $\begin{array}{l}\text { Equity }(n=97) \\
M(\mathrm{SD})\end{array}$ \\
\hline Anger & $2.53(1.17)^{\mathrm{a}}$ & $1.07(0.36)^{\mathrm{b}}$ \\
& $95 \% \mathrm{CI}[2.29,2.76]$ & $95 \% \mathrm{CI}[1.00,1.14]$ \\
Compensation & $40.0 \%$ & $3.1 \%$ \\
Punishment & $7.4 \%$ & $0 \%$ \\
Self & $52.6 \%$ & $96.9 \%$ \\
& $\chi^{2}(2, N=192)=50.31, p<0.001$ & \\
\hline
\end{tabular}

Anger scores could range from 1 (not at all) to 5 (very strongly). Means with a different superscript differ significantly from each other, $t(111.51)=11.63, p<0.001$

Participants in the equity condition read the same scenario, but here Mark decided to give Rick $€ 50$ and keep $€ 50$. Next, as an emotion check, participants indicated how much anger, shame, regret, pride, and guilt they would feel $(1=$ not at all, $5=$ very strongly).

Then, participants read that they owned $€ 50$ and they could choose to compensate Rick or punish Mark, or keep all the money themselves. In the case of choosing punishment or compensation, participants also indicated how many euros they would spend (Every euro used would de/increase the other's amount with $€ 3$ ). Finally, participants were thanked, debriefed, and received $€ 8$ or course credit for their participation.

\subsection{Results}

The results are displayed in Table 2. The other emotion means are in the Appendix. Participants in the inequity condition reported more anger than their counterparts in the equity condition, and they reported more anger than all other emotions. Participants in the inequity condition punished Mark and compensated Rick more often than participants in the equity condition. Most equity participants chose to keep the money. When we only consider participants who were confronted with inequity and chose to not keep their entire money, results show that they opted more often for compensation $(84 \%)$ than punishment $(16 \%),{ }^{5} \chi^{2}(1, N=45)=21.36, p<0.001$.

\subsection{Discussion}

These results show that participants that become angry after inequity prefer compensation to punishment, whereas such a preference is absent in the equity condition.

\footnotetext{
5 Due to the low number of participants choosing for punishment, we were not able to compare the amount of money used for compensation and punishment.
} 
Together, these studies support our hypothesis that third-party anger can elicit prosocial behavior aimed at the victim and to a preference for prosocial behavior over antagonistic behavior in order to restore equity.

Importantly, however, our studies did not rely on actual behavior with some level of consequence. Put differently, our studies were not properly incentivized. To provide final support for our hypothesis, Study 3 provides a direct measure of behavior by inviting participants to actually use their monetary endowment for third-party interventions to increase the trade-off between keeping money to take home or using it for justice-related behavior. Therefore, it provides an objective and clear behavioral measure that indicates if participants are willing to sacrifice their own resources for the sake of re-dressing the injustice and whether that takes the form of punishment or compensation (or some combination of the two).

\section{Study 3}

\subsection{Method}

German university students (36 males, 52 females; $M_{\text {age }}=23.14$, SD $=2.81$ ) participated in an experimental game. We tested their willingness to engage in costly third-party interventions using a modified altruistic intervention paradigm (see Lotz et al. 2011a,b; Fehr and Gächter 2002). Upon arriving, participants were told that they had been randomly assigned to the role of "Person C" in a study involving three anonymous strangers. They were told that Person B had been initially allocated $€ 10$, but that Person A was given the opportunity to redistribute that $€ 10$ to him/herself and Person B (i.e., to take some or all money away from Person B). Participants were told that Person A had taken the entire $€ 10$, leaving nothing to Person B. After our participants learnt about the unfair behavior of Person A, we assessed their anger, amongst other emotions $(1=$ not at all, $5=$ very much $)$.

Participants were then given their own endowment of $€ 5$ in cash using coins of various denomination. It was explained to them that, if they wanted, they could reallocate their initial endowment to punish the offender, compensate the victim, some combination of the two, or to keep it for themselves (i.e., they could keep any money they chose not reallocated to punishment or compensation). Punitive and compensatory actions were made more efficient (consistent with experimental games involving actual behavior, e.g., Fehr and Gächter 2002) so that each $€ 0.50$ reallocation resulted in a $€ 1$ consequence (e.g., $€ 1.50$ punishment allocation yielded in a loss for Person A of $€ 3)$.

\subsection{Results}

The results are summarized in Table 3. Emotion means are displayed in the Appendix. In total, out of 88 participants 22 did not use any money for re-allocation, 4 only punished Person A, 28 only compensated Person B, and 34 punished Person A as well as compensated Person B. Thus, a total of 66 participants (75\%) engaged in at least one justice response. On average, participants used $€ 0.75(\mathrm{SD}=1.13)$ for punishment 
Table 3 Study 3: percentages of monetary division and reported anger

\begin{tabular}{lr}
\hline Participants who chose... & $n$ \\
\hline$\ldots$ compensation only & 28 \\
$\ldots$ punishment only & 4 \\
$\ldots$.compensation and punishment & 34 \\
$\ldots$ no justice response & 22 \\
\hline
\end{tabular}

and $€ 1.14$ ( $\mathrm{SD}=1.17$ ) for compensation. Thus, consistent with the previous studies, compensation seems the preferred option. Furthermore, we found a positive relationship of anger and third-party interventions. That is, the total amount of money used for third-party interventions significantly correlated with anger, $r(88)=0.32, p=0.001$.

In sum, this behavioral study replicated and augmented the previous results and suggests that third-party interventions follow experiences of anger. As in previous research, compensation was a preferred option, allowing the conclusion that anger can function as a prosocial emotion associated with the willingness to engage in costly third-party behavior.

\section{General discussion}

We examined prosocial consequences of third-party anger. In Study 1, we found that autobiographical recalls of anger spill over to new situations and cause participants to act more prosocially in triadic situations. Interestingly, these effects could not be explained by trait anger and trait empathy. Study 2 elaborated on that and revealed that people angry about a triadic situation of inequity prefer compensation of a victim to punishment of a perpetrator. Finally, Study 3 provides behavioral evidence that people are willing to give up money in order to compensate others, who have been unfairly treated. This willingness was correlated with experiences of anger elicited by this unfair treatment.

These findings add to the existing literature in that they are the first to show when anger motivates people to compensate or act prosocially towards the victim. We think that these prosocial consequences of anger have been overlooked in previous studies on the negative consequences of anger because these focused on dyadic situations where the participant is the victim. Only in triadic situations when a person observes an inequity can we observe prosocial behavior following from anger. When people themselves are victims of inequity, we primarily see antagonistic behavior because there is simply no victim to be compensated (unless one could compensate oneself). An additional reason for having overlooked prosocial consequences of anger could be the dominant theoretical focus on negative consequences of anger, most notably punishment. Previous studies that did look at positive or prosocial effects of anger were mainly correlational in nature, were inconsistent in the operationalization of anger (e.g., Iyer et al. 2007; Montada and Schneider 1989; Wakslak et al. 2007), lacked a simultaneous measure of both compensatory and punitive measures (as in third-party punishment studies), or the compensatory and punitive measures were not costly (e.g., Adams and Mullen 2014). Finally, studies that did include positive 
consequences typically did not directly measure situational, state anger. For example, Leliveld et al. (2012) and Prooijen (2010) looked at prosocial consequences after injustice but did not include a measurement of anger. Deffenbacher et al. (1996) showed a positive correlation between trait anger and aggressive consequences, and Vitaglione and Barnett (2003) showed that there was no direct relation between trait empathic anger and helping or punishing. As has been shown for other emotions, such as shame, trait measures tend to yield different results than state measures of emotion (e.g., De Hooge et al. 2008). Effect of trait anger show what people do who are easily angered or who experience anger often. Effects of state anger show what people do who are actually angry about a specific situation.

By showing that anger has prosocial consequences we do not propose that anger is a prosocial emotion, neither do we suggest that there are two different forms of anger, or that anger leads to a general tendency to act prosocial to anyone or in every situation. Instead, we merely argue that there are situational distinctions in the experience of anger allowing for certain behaviors to emerge. Prosocial behavior can only emerge when there is room for compensatory behavior towards the victim and not only punitive behavior towards the perpetrator (as reflected in the difference between triadic situations and dyadic situations). Furthermore, as discussed previously and revealed in our studies, the positive effects of anger cannot be explained by simultaneous experiences of trait empathic concern. One could argue that state empathic concern might influence prosocial consequences above and beyond state anger. However, if so we would predict more compensation in the control condition of Study 1 as well, which was not the case.

In addition to finding a direct relation between anger and prosocial behavior, we also found that angry people prefer compensation to punishment. Compensation could be seen as a more efficient form of restoring equity than punishment is, as it allows for getting the victim out of its disadvantageous position. Punishment, on the other hand, only lowers the perpetrator's position to that of the victim, but does not do anything for the victim. However, there is also a possibility that people prefer compensation to punishment due to relational concerns. In contrast to punishment, compensation allows for investing in a relationship with the victim. Future research might reveal the exact motivation behind this preference.

Taken together, we sought to comprehend the behavioral effects of anger, and how situational factors decide why anger leads to antagonistic behavior towards the perpetrator or prosocial behavior towards the victim. These studies suggest that the behaviors stemming from anger, be it antagonistic or prosocial, are a situation-specific reaction to inequity.

\section{Compliance with ethical standards}

Conflict of interest The authors declare no conflict of interest.

Ethical approval All procedures performed in studies involving human participants were in accordance with the ethical standards of the institutional and/or national research committee and with the 1964 Helsinki declaration and its later amendments or comparable ethical standards. 
Open Access This article is distributed under the terms of the Creative Commons Attribution 4.0 International License (http://creativecommons.org/licenses/by/4.0/), which permits unrestricted use, distribution, and reproduction in any medium, provided you give appropriate credit to the original author(s) and the source, provide a link to the Creative Commons license, and indicate if changes were made.

\section{Appendix}

\section{Emotion manipulation checks of Studies 1-3 (Tables 4, 5, 6)}

Table 4 Study 1: means (and standard deviations) of emotions experienced as a function of condition

\begin{tabular}{|c|c|c|c|c|}
\hline \multirow[t]{3}{*}{ Emotions } & \multicolumn{4}{|l|}{ Condition } \\
\hline & \multicolumn{2}{|c|}{ Anger $(n=63)$} & \multicolumn{2}{|c|}{ Control $(n=59)$} \\
\hline & $M(\mathrm{SD})$ & $95 \% \mathrm{CI}$ & $M(\mathrm{SD})$ & $95 \% \mathrm{CI}$ \\
\hline Anger & $3.67(0.92)^{\mathrm{a}}$ & {$[3.44,3.90]$} & $1.29(0.74)^{\mathrm{b}}$ & {$[1.09,1.48]$} \\
\hline Guilt & $1.67(1.03)^{\mathrm{a}}$ & {$[1.41,1.93]$} & $1.24(0.60)^{\mathrm{b}}$ & {$[1.08,1.39]$} \\
\hline Shame & $1.89(1.06)^{\mathrm{a}}$ & {$[1.62,2.16]$} & $1.29(0.70)^{\mathrm{b}}$ & {$[1.11,1.47]$} \\
\hline Regret & $2.08(1.22)^{\mathrm{a}}$ & {$[1.77,2.39]$} & $1.42(0.79)^{\mathrm{b}}$ & {$[1.22,1.63]$} \\
\hline Sadness & $2.57(1.36)^{\mathrm{a}}$ & {$[2.23,2.92]$} & $1.25(0.71)^{\mathrm{b}}$ & {$[1.07,1.44]$} \\
\hline Happiness & $1.25(0.62)^{\mathrm{a}}$ & {$[1.10,1.41]$} & $3.29(0.95)^{b}$ & {$[3.04,3.54]$} \\
\hline
\end{tabular}

Emotions could range from 1 (not at all) to 5 (very strongly). Means with a different superscript differ significantly with all $t \mathrm{~s}>2.84, p \mathrm{~s}<0.006$. Means in bold represent the dominant emotion experienced within that condition, with all $t \mathrm{~s}>8.12, p \mathrm{~s}<0.001$ in the anger condition, and with all $t \mathrm{~s}>10.36, p \mathrm{~s}<$ 0.001 in the control condition

Table 5 Study 2: means (and standard deviations) of emotions experienced as a function of condition

\begin{tabular}{|c|c|c|c|c|}
\hline \multirow[t]{3}{*}{ Emotions } & \multicolumn{4}{|l|}{ Condition } \\
\hline & \multicolumn{2}{|c|}{ Inequity $(n=95)$} & \multicolumn{2}{|c|}{ Equity $(n=97)$} \\
\hline & $M(\mathrm{SD})$ & $95 \% \mathrm{CI}$ & $M(\mathrm{SD})$ & $95 \% \mathrm{CI}$ \\
\hline Anger & $2.53(1.17)^{\mathrm{a}}$ & {$[2.29,2.76]$} & $1.07(0.36)^{b}$ & {$[1.00,1.14]$} \\
\hline Guilt & $2.05(1.20)^{\mathrm{a}}$ & {$[1.81,2.30]$} & $1.26(0.70)^{\mathrm{b}}$ & {$[1.12,1.40]$} \\
\hline Shame & $1.67(1.02)^{\mathrm{a}}$ & {$[1.47,1.88]$} & $1.22(0.56)^{b}$ & {$[1.10,1.33]$} \\
\hline Regret & $1.53(0.85)^{\mathrm{a}}$ & {$[1.35,1.70]$} & $1.39(0.76)^{\mathrm{a}}$ & {$[1.24,1.54]$} \\
\hline Pride & $1.36(0.74)^{\mathrm{a}}$ & {$[1.21,1.51]$} & $2.81(1.32)^{b}$ & {$[2.55,3.08]$} \\
\hline
\end{tabular}

Emotions could range from 1 (not at all) to 5 (very strongly). Means with a different superscript differ significantly with all $t \mathrm{~s}>3.85, p \mathrm{~s}<0.001$. Means in bold represent the dominant emotion experienced within that condition, with all $t \mathrm{~s}>2.84, p \mathrm{~s}<0.005$ in the anger condition, and with all $t \mathrm{~s}>10.80, p \mathrm{~s}<$ 0.001 in the control condition 
Table 6 Study 3: means (and standard deviations) of emotions experienced as a consequence of the presented injustice

\begin{tabular}{lll}
\hline Experimental game $(n=88)$ & & \\
\hline Emotions & $M(\mathrm{SD})$ & $95 \% \mathrm{CI}$ \\
\hline Anger & $\mathbf{2 . 4 2 ( 1 . 2 2 )}$ & {$[\mathbf{2 . 1 6 , 2 . 6 8}]$} \\
Guilt & $1.27(0.66)$ & {$[1.13,1.41]$} \\
Shame & $1.73(1.00)$ & {$[1.51,1.94]$} \\
Fear & $1.19(0.50)$ & {$[1.08,1.29]$} \\
Pride & $1.34(0.86)$ & {$[1.16,1.52]$}
\end{tabular}

Emotions could range from 1 (not at all) to 5 (very strongly). Means in bold represent the dominant emotion experienced within that condition in comparison to emotions collected in the previous studies, with all $t \mathrm{~s}>$ 5.76, $p \mathrm{~s}<0.001$. Study 4 included a longer list of emotions that served as filler items, which is disclosed here. These additional emotions were active $(M=2.24, \mathrm{SD}=1.22)$, distressed $(M=2.48, \mathrm{SD}=1.08)$, interested $(M=3.00, \mathrm{SD}=1.09)$, happy $(M=1.49, \mathrm{SD}=0.84)$, strong $(M=2.24, \mathrm{SD}=1.20)$, shocked $(M=2.05, \mathrm{SD}=1.24)$, hostile $(M=1.81, \mathrm{SD}=1.08)$, stimulated $(M=2.27, \mathrm{SD}=1.07)$, aggravated $(M=1.86, \mathrm{SD}=0.98)$, enthusiastic $(M=1.25, \mathrm{SD}=0.65)$, awake $(M=2.93, \mathrm{SD}=1.20)$, nervous $(M$ $=1.67, \mathrm{SD}=1.00)$, determined $(M=2.75, \mathrm{SD}=1.22)$, attentive $(M=3.25, \mathrm{SD}=1.07)$, and confused $(M=1.85, \mathrm{SD}=1.19)$

\section{References}

Adams, G. S., \& Mullen, E. (2014). Punishing the perpetrator decreases compensation for victims victims. Social Psychological and Personality Science, 6, 31-38. https://doi.org/10.1177/1948550614542346.

Averill, J. R. (1982). Anger and aggression: An essay on emotion. New York: Springer.

Baron, J. (1995). Blind justice: fairness to groups and the do-no-harm principle. Journal of Behavioral Decision Making, 8, 71-83. https://doi.org/10.1002/bdm.3960080202.

Batson, C. D., Kennedy, C. L., Nord, L., Stocks, E. L., Fleming, D. A., Marzette, C. M., et al. (2007). Anger at unfairness: Is it moral outrage? European Journal of Social Psychology, 37, 1272-1285. https:// doi.org/10.1002/ejsp.434.

Berkowitz, L. (1990). On the formation and regulation of anger and aggression. A cognitiveneoassociationistic analysis. American Psychologist, 45, 494-503. https://doi.org/10.1037/0003066X.45.4.494.

Berkowitz, L., \& Harmon-Jones, E. (2004). Toward an understanding of the determinants of anger. Emotion, 4, 107-130. https://doi.org/10.1037/1528-3542.4.2.107.

Blader, S. L., \& Tyler, T. R. (2002). Justice and empathy: What motivates people to help others? In M. Ross \& D. T. Miller (Eds.), The justice motive in everyday life (pp. 226-250). Cambridge: Cambridge University Press.

Bougie, R., Pieters, R., \& Zeelenberg, M. (2003). Angry customers don't come back, they get back: The experience and behavioral implications of anger and dissatisfaction in services. Journal of the Academy of Marketing Science, 31, 377-393. https://doi.org/10.1177/0092070303254412.

Carver, C. S., \& Harmon-Jones, E. (2009). Anger is an approach-related affect: Evidence and implications. Psychological Bulletin, 135, 183-204. https://doi.org/10.1037/a0013965.

Darley, J. M., \& Pittman, T. S. (2003). The psychology of compensatory and retributive justice. Personality and Social Psychology Review, 7, 324-336. https://doi.org/10.1207/S15327957PSPR0704_05.

Davis, M. H. (1983). Measuring individual differences in empathy: Evidence for a multidimensional approach. Journal of Personality and Social Psychology, 44, 113-126. https://doi.org/10.1037/00223514.44.1.113.

Davis, M. H. (1994). Empathy: A social psychological approach. Madison, WI: Brown and Benchmark publishers.

Deffenbacher, J. L., Oetting, E. R., Lynch, R. S., \& Morris, C. D. (1996). The expression of anger and its consequences. Behaviour Research and Therapy, 34, 575-90. https://doi.org/10.1016/00057967(96)00018-6. 
De Hooge, I. E., Breugelmans, S. M., \& Zeelenberg, M. (2008). Not so ugly after all: When shame acts as a commitment device. Journal of Personality and Social Psychology, 95, 933-943. https://doi.org/10. 1037/a0011991.

Eisenberg, N., \& Fabes, R. A. (1990). Empathy: Conceptualization, measurement, and relation to prosocial behavior. Motivation and Emotion, 14, 131-149. https://doi.org/10.1007/BF00991640.

Feldman Hall, O., Sokol-Hessner, P., Van Bavel, J. J., \& Phelps, E. A. (2014). Fairness violations elicit greater punishment on behalf of others than for oneself. Nature Communications, 5, 5306.

Fehr, E., \& Fischbacher, U. (2004). Third-party punishment and social norms. Evolution and Human Behavior, 25, 63-87. https://doi.org/10.1016/S1090-5138(04)00005-4.

Fehr, E., \& Gächter, S. (2002). Altruistic punishment in humans. Nature, 415, 137-40. https://doi.org/10. 1038/415137a.

Fischer, A. H., \& Roseman, I. J. (2007). Beat them or ban them: The characteristics and social functions of anger and contempt. Journal of Personality and Social Psychology, 93, 103-115. https://doi.org/10. 1037/0022-3514.93.1.103.

Frijda, N. H. (1986). The emotions. Cambridge, UK: Cambridge University Press.

Frijda, N. H. (1987). Emotion, cognitive structure, and action tendency. Cognition and Emotion, 1, 115-143. https://doi.org/10.1080/02699938708408043.

Frijda, N. H. (2004). Emotions and action. In A. S. R. Manstead, N. Frijda, \& A. Fischer (Eds.), Feelings and emotions (pp. 158-173). Cambridge, UK: Cambridge University Press.

Frijda, N. H., \& Zeelenberg, M. (2001). Appraisal: What is the dependent? In K. R. Scherer, A. Schorr, \& T. Johnstone (Eds.), Appraisal processes in emotion: Theory, methods, research. Series in affective science (pp. 141-155). New York: Oxford University Press.

Iyer, A., Schmader, T., \& Lickel, B. (2007). Why individuals protest the perceived transgressions of their country: The role of anger, shame, and guilt. Personality and Social Psychology Bulletin, 33, 572-587. https://doi.org/10.1177/0146167206297402.

Izard, C. E. (1991). The psychology of emotions. New York: Planum Press.

Kuppens, P., Van Mechelen, I., Smits, D. J. M., \& De Boeck, P. (2003). The appraisal basis of anger: Specificity, necessity and sufficiency of components. Emotion, 3, 254-269. https://doi.org/10.1037/ 1528-3542.3.3.254.

Leliveld, M. C., Van Dijk, E., \& Van Beest, I. (2012). Punishing and compensating others at your own expense: The role of empathic concern on reactions to distributive injustice. European Journal of Social Psychology, 42, 135-140. https://doi.org/10.1002/ejsp.872.

Lemay, E. P., Overall, N. C., \& Clark, M. S. (2012). Experiences and interpersonal consequences of hurt feelings and anger. Journal of Personality and Social Psychology, 103, 982-1006. https://doi.org/10. $1037 / \mathrm{a} 0030064$.

Lotz, S., Baumert, A., Schlösser, T., Gresser, F., \& Fetchenhauer, D. (2011a). Individual differences in thirdparty interventions: How justice sensitivity shapes altruistic punishment. Negotiation and Conflict Management Research, 4, 297-313.

Lotz, S., Okimoto, T. G., Schlösser, T., \& Fetchenhauer, D. (2011b). Punitive versus compensatory reactions to injustice: Emotional antecedents to third-party interventions. Journal of Experimental Social Psychology, 47, 477-480. https://doi.org/10.1016/j.jesp.2010.004.

Martinez, L. F., \& Zeelenberg, M. (2015). Trust me (or not): Regret and disappointment in experimental economic games. Decision, 2, 118-126. https://doi.org/10.1037/dec0000025.

Mikula, G., Scherer, K. R., \& Athenstaedt, U. (1998). The role of injustice in the elicitation of differential emotional reactions. Personality and Social Psychology Bulletin, 24, 769-783. https://doi.org/10. $1177 / 0146167298247009$.

Montada, L., \& Schneider, A. (1989). Justice and emotional reactions to the disadvantaged. Social Justice Research, 3, 313-344. https://doi.org/10.1007/BF01048081.

Nelissen, R. M. A., \& Zeelenberg, M. (2009). Moral emotions as determinants of third-party punishment: Anger, guilt, and the functions of altruistic sanctions. Judgment and Decision Making, 4, 543-553. http://journal.sjdm.org/91001/jdm91001.pdf

O’Mara, E. M., Jackson, L. E., Batson, C. D., \& Gaertner, L. (2011). Will moral outrage stand up? Distinguishing among emotional reactions to a moral violation. European Journal of Social Psychology, 41, 173-179. https://doi.org/10.1002/ejsp.754.

Pillutla, M., \& Murnighan, J. K. (1996). Unfairness, anger, and spite: Emotional rejections of ultimatum offers. Organizational Behavior and Human Decision Processes, 68, 208-224. https://doi.org/10. 1006/obhd.1996.0100. 
Rimé, B. (2009). Emotion elicits the social sharing of emotion: Theory and empirical review. Emotion Review, 1, 60-85. https://doi.org/10.1177/1754073908097189.

Roseman, I. J., Wiest, C., \& Swartz, T. S. (1994). Phenomenology, behaviors, and goals differentiate discrete emotions. Journal of Personality and Social Psychology, 67, 206-221. https://doi.org/10.1037//00223514.67.2.206.

Russell, J. A. (1991). Culture and the categorization of emotions. Psychological Bulletin, 110, 426-450. https://doi.org/10.1037/0033-2909.110.3.426.

Scherer, K. R. (1993). Studying the emotion-antecedent appraisal process: An expert system approach. Cognition and Emotion, 7, 325-355. https://doi.org/10.1080/02699939308409192.

Schimmack, U., \& Diener, E. (1997). Affect intensity: Separating intensity and frequency in repeatedly measured affect. Journal of Personality and Social Psychology, 73, 1313-1329. https://doi.org/10. 1037//0022-3514.73.6.1313.

Spielberger, C. D. (1988). Manual for the State-TraitAnger Expression Inventory. Odessa, FL: Psychological Assessment Resources.

Stillwell, A. M., Baumeister, R. F., \& Del Priore, R. E. (2008). We're all victims here: Toward a psychology of revenge. Basic and Applied Social Psychology, 30, 253-263. https://doi.org/10.1080/ 01973530802375094.

Strack, F., Schwarz, N., \& Gschneidinger, E. (1985). Happiness and reminiscing: The role of time perspective, affect, and mode of thinking. Journal of Personality and Social Psychology, 49, 1460-1469. https://doi.org/10.1037//0022-3514.49.6.1460.

Van Coillie, H., \& Van Mechelen, I. (2006). A taxonomy of anger-related behaviors in young adults. Motivation and Emotion, 30, 57-74. https://doi.org/10.1007/s11031-006-9000-6.

Van Doorn, J., Zeelenberg, M., \& Breugelmans, S. M. (2014). Anger and prosocial behavior. Emotion Review, 6, 261-268. https://doi.org/10.1177/1754073914523794.

Van Prooijen, J.-W. (2010). Retributive versus compensatory justice: Observers' preference for punishing in response to criminal offenses. European Journal of Social Psychology, 40, 72-85. https://doi.org/ 10.1002/ejsp.611.

Vitaglione, G. D., \& Barnett, M. A. (2003). Assessing a new dimension of empathy: Empathic anger as a predictor of helping and punishing desires. Motivation and Emotion, 27, 301-325. https://doi.org/10. 1023/A:1026231622102.

Wakslak, C. J., Jost, J. T., Tyler, T. R., \& Chen, E. S. (2007). Moral outrage mediates the dampening effect of system justification on support for redistributive social policies. Psychological Science, 18, 267-274. https://doi.org/10.1111/j.1467-9280.2007.01887.x.

Wetzer, I. M., Zeelenberg, M., \& Pieters, R. (2007). "Never eat in that restaurant, I did!" Exploring why people engage in negative word-of-mouth communication. Psychology and Marketing, 24, 661-680. https://doi.org/10.1002/mar.20178. 